\title{
0 debate dos desencontros: uma avaliação das críticas de Michal Sandel ao liberalismo de John Rawls
}

Flávio Azevedo Reis

flavio_a_reis@hotmail.com

Universidade do Estado de São Paulo (USP), São Paulo, Brasil

resumo 0 principal objetivo de Micheal Sandel, no livro Liberalismo e os limites da justiça, foi atacar o conceito de deontologia de John Rawls. Nesse artigo, pretende-se argumentar que Sandel interpretou o conceito de deontologia de um modo equivocado. Há uma diferença entre a forma como Rawls definiu este conceito e a maneira como foi interpretado por Sandel. Dado isso, na primeira parte desse artigo, será analisado o modo como Sandel interpretou o conceito de deontologia na filosofia de Rawls. A segunda parte apresenta uma avaliação do confronto entre os dois autores à luz da diferença no modo como ambos compreendem o significado da deontologia no liberalismo político.

palavras chave Liberalismo; Comunitarismo; John Rawls; Michael Sandel; Deontologia; Teoria da Justiça

\section{1) A crítica}

É notório que Rawls, no livro O liberalismo político, negou que as mudanças em sua filosofia pudessem ser atribuídas às críticas dos autores comunitaristas. Ao mencionar Michael Sandel, Rawls insiste que ele não compreendeu adequadamente o seu projeto filosófico. Suas respostas ressaltam erros na interpretação da ideia de "prioridade do correto (right)" e no papel da concepção de pessoa no construtivismo kantiano. Neste artigo, pretendo argumentar que Rawls definiu o conceito de deontologia (e a prioridade do correto) de um modo distinto do interpretado por Sandel. Se esta hipótese estiver correta, talvez seja possível interpretar a ênfase que 
Rawls atribuiu à relação entre o correto e o bem como uma tentativa de desmentir a leitura proposta por Sandel, que define a deontologia como a independência entre o correto e o bem. (v. RAWLS, 1996, pp.173-8; V, $\$ \$$ 1-2). O principal objetivo aqui é entender como as divergências na interpretação do conceito de deontologia poderiam auxiliar nossa compreensão das questões filosóficas que definem o debate entre os dois autores. Com isso, pretendo apontar que o modo como Sandel descreve os objetivos do liberalismo político de Rawls poderia levar os seus leitores a uma compreensão inadequada do projeto filosófico rawlsiano. ${ }^{1}$

No livro Uma teoria da justiça, Rawls definiu o conceito de deontologia a partir da distinção entre três conceitos da ética: correto (right), bem e dignidade moral (moral worth). As concepções teleológicas consideram o conceito do bem como independente do correto, e o conceito do correto como um meio para realização do bem. Para Rawls, uma concepção deontológica nega a teleologia, ou seja, ela nega a independência do bem e/ou o papel instrumental do correto como meio para realização do bem. Um dos principais objetivos do livro Uma teoria da justiça foi propor uma estrutura alternativa dos conceitos éticos que, por oposição à teleologia, deveria atribuir prioridade ao correto em relação ao bem. Isso significa que uma teoria deontológica estava preocupada, em primeiro lugar, com a relação adequada entre os conceitos de correto e bem, não com sua independência ou separação.

Michael Sandel, por outro lado, interpreta a deontologia como a fundamentação do correto independente do bem. Segundo a sua interpretação, Rawls segue uma concepção kantiana de deontologia que identifica as concepções de bem como inclinações empíricas e contingentes. Uma concepção deontológica de justiça não poderia derivar os seus princípios a partir do bem, pois isso iria eliminar a sua capacidade crítica. O correto deve estar afastado das concepções contingentes e empíricas de bem, pois o seu objetivo é servir como critério para avaliar essas contingências. Há uma necessidade, Sandel argumenta, de distinguir claramente o critério de avaliação (correto) dos objetos avaliados (bem). Derivar o correto a partir do bem significaria reproduzir os valores já presentes nas concepções empíricas de bem e, portanto, solapar a capacidade crítica do correto enquanto critério de avaliação. Assim, Rawls teria aprendido com Kant que o poder crítico do correto está 
intimamente ligado ao modo como ele é fundamentado. O correto só poderá julgar adequadamente as concepções de bem, se ele tiver um fundamento independente delas.

A deontologia possui dois significados de acordo com Sandel: (1) o correto, como critério de avaliação, deve ser moralmente independente e anterior aos objetos que ele avalia. Ele representa deveres e proibições categóricas que precedem qualquer consideração prática. Nessa perspectiva, a deontologia se opõe ao consequencialismo; (2) para realizar a prioridade moral, o correto deve ser fundamentado de forma independente dos objetos que ele avalia. Nesse caso, ele deve ser independente de qualquer consideração em relação à boa vida. Nessa segunda perspectiva, a deontologia se opõe à teleologia. (v. SANDEL, 1998, p. 3). A leitura de Sandel pressupõe que Rawls combina ambos os significados da deontologia e, desse modo, assume uma tensão indelével entre contextualismo e universalismo. Por um lado, há a contingência empírica das diversas concepções de bem e dos diversos valores concorrentes que existem nas sociedades contemporâneas. Por outro, há a necessidade moral de apresentar o correto como critério de avaliação daqueles valores e práticas contingentes.

O ponto mais importante da leitura de Sandel é o seguinte: a forma pela qual se fundamenta a concepção de justiça esta ligada a uma concepção de pessoa. Para Sandel, o modo como uma teoria estabelece a relação entre a justiça (correto) e o bem depende da forma como é concebida a relação entre o sujeito e seus fins. Uma concepção de justiça derivada de forma a priori (sem nenhuma relação com os valores empiricamente dados em uma sociedade) depende, segundo Sandel, de uma noção de sujeito capaz de se desvincular totalmente de suas determinações empíricas (sujeito desencarnado). Por outro lado, uma concepção de justiça derivada a partir dos valores morais de uma determinada sociedade pressupõe uma concepção de sujeito como totalmente determinado pela sua situação empírica (sujeito radicalmente situado). Esta é uma tese central para a sua argumentação: a forma pela qual se deriva a concepção de justiça depende do modo como o sujeito é concebido. Uma concepção de justiça desvinculada da situação empírica depende de uma noção de sujeito também desvinculado de sua situação empírica. Uma concepção de justiça derivada das circunstâncias empíricas depende de uma noção de sujeito vinculado a essas mesmas circunstâncias. 
Sandel diz que ambas as alternativas são inaceitáveis para Rawls. Segundo ele, Rawls deve encontrar um "ponto arquimediano" entre elas. Para que a justiça possa servir como critério de avaliação, é necessário distinguir o critério de avaliação da coisa avaliada. Portanto, não é aceitável derivar a concepção de justiça a partir dos dados empíricos, pois isto resultaria apenas na justificação de práticas já existentes. Sem uma distinção clara entre o critério de avaliação e a coisa avaliada, a justiça não poderia servir como "ponto de vista crítico" a partir do qual se poderiam julgar as diversas concepções de bem. Por outro lado, seria igualmente insatisfatório derivar a concepção de justiça a partir de dados puramente abstratos, sem relação alguma com a realidade empírica a qual ela irá se aplicar. Uma derivação a priori seria infundada (groundless) (v. SANDEL, 1998, p. 17). O projeto teórico rawlsiano, segundo Sandel, consiste em formular uma concepção de justiça que, ao mesmo tempo, seria independente das circunstâncias empíricas (de modo que esta concepção de justiça sirva de ponto de vista crítico e garanta a primazia da justiça sobre o bem), mas também mantenha alguma relação com estas circunstâncias de forma que a concepção não se torne infundada e arbitrária. O desafio é encontrar um equilíbrio entre essas duas exigências antagônicas: uma concepção de justiça que, ao mesmo tempo, seja fundamentada independentemente dos valores pré-existentes em uma sociedade, mas que possa ser aplicável a uma sociedade real.

Segundo Sandel, Rawls teria combinado elementos em sua teoria que permitem pesar ambas as exigências. Por um lado, na posição original, as partes escolhem os princípios de justiça sob um "véu de ignorância" que as impede de saber quais são as suas concepções de bem, as suas localizações na sociedade, suas características psicológicas, etc. Isto garante que a decisão não seja diretamente vinculada a interesses empiricamente dados. A concepção de justiça escolhida neste contrato hipotético mantem uma certa independência em relação às condições empíricas. Por outro lado, a construção desta situação contratual (a posição original) leva em consideração as "circunstâncias da justiça”" (v. SANDEL, 1998, p. 29), ou seja, as condições de aplicação da concepção de justiça. Assim, a situação contratual inclui elementos que indicam a sua aplicação à sociedade e homens reais.

O problema do conflito entre fundamentação e aplicação ganha uma nova faceta neste momento. Se Rawls inclui considerações empíricas, sob a forma das "circunstâncias da justiça”, então a sua teoria abarcaria várias 
contradições. Seriam duas exigências aparentemente incompatíveis: por um lado, uma concepção afastada das contingências empíricas garante a primazia da justiça, mas pode se distanciar da condição real das sociedades humanas; por outro lado, uma concepção comprometida com o empírico pode garantir uma ligação com as circunstâncias reais, mas poderia excluir a primazia da justiça.

É esta combinação incerta que levanta as objeções que nós

consideramos, enquanto a concepção kantiana de lei moral e do reino dos fins parece negar à justiça a sua situação humana, a consideração humeana [David Hume] da situação humana parece ser incapaz de acomodar reivindicações fortes a favor da primazia da justiça. Porém, entender como estas inconsistências surgem não as dissolvem, mas apenas confirmam. Também poderia parecer que as duas aspirações da teoria de Rawls, evitar tanto as contingências dos desejos existentes e a suposta arbitrariedade e obscuridade do transcendente, são incombináveis. O ponto arquimediano seria eliminado em uma ladainha de contradições. (SANDEL, 1998, p. 40)

A solução de Rawls para estas contradições, segundo Sandel, é o método do equilíbrio reflexivo. A justificação da concepção de justiça pressupõe que nós possuímos crenças e valores morais, que se expressam na forma de juízos ponderados. Os pressupostos da teoria não estão sustentados em uma avaliação diretamente empírica da sociedade, mas sim em sua validade diante dos nossos juízos após a devida reflexão. Isso significa que os juízos ponderados podem incluir considerações empíricas acerca das circunstâncias para aplicação da justiça sem pressupor um teste diretamente empírico. A validade dessas considerações é dada pelos juízos em equilíbrio reflexivo, que não dependem diretamente de dados empíricos fornecidos pela sociologia ou psicologia. Sandel argumenta que a inclusão de pressupostos empíricos não solapa a força deontológica da teoria porque eles não são plenamente empíricos. Esses pressupostos são apenas as nossas crenças e valores acerca das circunstâncias sociais. A justiça pode, desse modo, fazer uma referência às condições de sua aplicação sem destruir a independência do correto.

Para Sandel, o método do equilíbrio reflexivo resolveu a tensão entre as exigências universalista e contextualista na filosofia de Rawls. Ele não 
acredita que Rawls buscou uma fundamentação de princípios de justiça completamente descolada da realidade, e o principal alvo de sua crítica não é uma suposta pretensão universalista na filosofia de Rawls. Pelo contrário, a interpretação de Sandel apresenta a filosofia de Rawls como a combinação do melhor dos dois mundos, ou seja, a força moral da filosofia kantiana e o realismo da empiria de David Hume. Assim, Sandel considera que Rawls forneceu uma solução satisfatória para essa questão. A sua crítica ao liberalismo se volta contra outro ponto: a divisão entre o correto e o bem. Ele acredita que o liberalismo pretende separar o correto do bem, mas é incapaz de fazê-lo.

Para Sandel, a forma como se constrói uma concepção de justiça está intimamente ligada a uma concepção de pessoa. Se Rawls deseja encontrar um "ponto arquimediano" entre duas formas inaceitáveis de fundamentar a justiça (totalmente empírica ou totalmente a priori), então ele também necessita de uma concepção de sujeito que seja um "ponto arquimediano" entre o sujeito desencarnado (totalmente descolado das condições empíricas) e um sujeito radicalmente situado (totalmente inserido nas circunstâncias empíricas). Segundo Sandel, Rawls não expôs a sua concepção de sujeito. Assim, ele pretende investigar as entrelinhas da filosofia rawlsiana em busca da concepção de pessoa implícita ali. $\mathrm{O}$ equilíbrio reflexivo serve como ponte para encontrar essa concepção de pessoa. Dado que a justiça como equidade deve refletir os nossos juízos morais ponderados, a concepção rawlsiana de pessoa estará entre esses juízos.

Antes de prosseguir, devemos deixar claro o modo como Sandel entende o estatuto da concepção de pessoa. Os pressupostos da teoria não são avaliados diretamente em relação às condições empíricas, mas são mediados pelo que Rawls chama de "convicções ponderadas". Desta forma, a validade destes pressupostos não é estritamente empírica, mas diz respeito a estas crenças acerca da justiça. Esta mediação permite que a exigência de aplicação não se torne tão destrutiva à exigência de fundamentação. Assim, a concepção de pessoa que Sandel pretende encontrar na teoria de Rawls não diz respeito à natureza real do ser humano, nem pretende ser validada pela psicologia ou sociologia. A concepção de pessoa reflete nossas crenças e conviç̧ões, que devem ser plausíveis, ou seja, devem ter alguma relação com a realidade, porém não uma relação direta. 
Podemos colocar o nosso problema desta forma: como o equilíbrio reflexivo deixa claro, as condições da posição original não podem ser tão imunes às circunstâncias humanas reais de forma que qualquer pressuposto que produza princípios de justiça seja aceito. A não ser que as premissas tenham alguma semelhança com a condição de criaturas dicernivelmente humanas, o sucesso do equilíbrio é, desta maneira, debilitado. (SANDEL, 1998, p.43)

Segundo Sandel, a concepção de pessoa está mais próxima de uma "antropologia filosófica” do que de uma ciência empírica. (SANDEL, 1998, p. 50)

Devemos notar que o uso da expressão "antropologia filosófica” revela um ponto importante: Sandel considera a concepção de pessoa como uma espécie de "natureza humana". Ela regula todos os aspectos da vida de um indivíduo. Assim, a concepção de pessoa pressuposta nos juízos ponderados terá consequências não apenas para a concepção política de justiça, mas também para as concepções de bem de um indivíduo. A forma como ele compreende a sua relação com o mundo será completamente influenciada pela concepção de pessoa presente em seus juízos ponderados. Ao formular uma concepção de natureza humana para fundamentar os princípios de justiça, Rawls também formula uma concepção que determina o modo como os indivíduos concebem a boa vida. Veremos abaixo que esse pressuposto implícito na crítica de Sandel é um ponto importante para avaliação de sua crítica.

A concepção de pessoa que Sandel identifica na teoria de Rawls, além de ser somente uma concepção "plausível” sustentada por nossas convicções ponderadas, também reflete o "ponto arquimediano". Assim como a justiça, a pessoa não pode estar totalmente descolada das circunstâncias empíricas, e também não pode estar totalmente vinculada a elas. A concepção de pessoa não pode ser a de um self [eu] totalmente independente de sua situação (sujeito desencarnado), nem um self totalmente determinado por ela (sujeito radicalmente situado). Uma questão central para a construção de uma teoria da justiça é a forma como ela define a relação entre o sujeito e os seus fins, isto é, a relação entre o self e as concepções de bem. Podemos formular uma concepção de justiça independente do bem, se o sujeito for distinto dos fins que ele persegue. Assim, poderíamos 
derivar a concepção de justiça a partir deste sujeito e não fazer referência às concepções de bem que ele segue. Se não distinguirmos o self de seus fins, só poderíamos derivar concepções de justiça ligadas às concepções de bem e, desse modo, não seria possível que a justiça e o correto tenham prioridade sobre o bem. As mesmas exigências contraditórias que vimos na construção da teoria da justiça surgem aqui na formulação da concepção de pessoa. Neste caso, é preciso encontrar uma concepção de sujeito que seja o meio termo entre estas duas concepções inaceitáveis. O ponto arquimediano é, segundo Sandel, o "sujeito de possessão": o self que escolhe os seus fins. Desta forma, o self é distinto de seus fins, pois ele é o agente de escolha. Por outro lado, ele está ligado aos fins, porque eles são os objetos da escolha do self. ${ }^{2}$

$\mathrm{Na}$ visão de Rawls, qualquer descrição do self e seus fins deve nos dizer duas coisas: como o selfé distinto de seus fins, e como o selfé conectado com seus fins. Sem a primeira, nós teríamos um sujeito radicalmente situado; sem a segunda, um sujeito radicalmente desencarnado. A solução de Rawls, implícita no desenho da posição original, é conceber o self como um sujeito de possessão, pois, enquanto possuidor, o self esta distante dos seus fins sem estar desconectado deles. (SANDEL, 1998, p. 54)

Isto significa que Rawls se baseia em uma concepção de pessoa na qual o sujeito escolhe os seus fins. Ele está distante das concepções de bem porque seu self é anterior aos seus fins, porém ele se conecta aos seus fins por um ato de vontade.

Para Sandel, essa concepção de pessoa contradiz o conceito de deontologia. Ele supõe que uma concepção deontológica não deveria estar vinculada a uma concepção de bem. Assim, ao identificar o "sujeito de possessão", Sandel argumenta que Rawls incluiu uma definição do bem em sua filosofia. Para mostrar isto, Sandel expõe dois tipos de ação (agency) humana: 1) dimensão voluntarista de ação: o sujeito está separado de seus fins e se conecta com eles por meio de uma escolha, ele se conecta aos seus fins como um sujeito que escolhe (willing subject). "A ação relevante envolve um exercício da vontade, pois é a vontade que é capaz de transcender o espaço entre o sujeito e seu objeto sem fechá-lo" (SANDEL, 1998, p. 58). Temos, então, uma definição do bem como "algo que é escolhido". Mesmo que não possamos determinar o que é este "algo", ainda 
temos uma definição do que é o bem;2) dimensão cognitiva de ação: o fim é um dado anterior ao sujeito. Não se obtém o fim por meio de uma escolha, mas por autoconhecimento:

Quando os fins do self são dados anteriormente, a ação relevante não é voluntária, mas sim cognitiva. Pois o sujeito não conquista autocomando pela escolha do que já está dado, mas pela reflexão em si mesma e pela investigação de sua natureza constitutiva, discernindo suas leis e imperativos, e reconhecendo seus propósitos por si mesmos. (SANDEL, 1998, p. 58)

Conceber a pessoa como um "sujeito de possessão" significa considerar apenas a "dimensão voluntarista da ação". Isto implica que concepções de bem ligadas a uma "dimensão cognitiva da ação" não poderiam ser aceitas. A opção pelo "sujeito de possessão" implica na aceitação de um conjunto determinado de concepções de bem ligado a uma dimensão voluntarista da ação e, desse modo, a exclusão de concepções de bem ligadas ao autoconhecimento. Dizer que é da "natureza humana" escolher os seus fins significa dizer que o bem não pode ser descoberto por autorreflexão.

Além disso, a concepção de sujeito de possessão também exerce influência sobre a relação dos indivíduos com a sociedade. Dizer que o self é anterior aos seus fins significa dizer que a identidade do sujeito está distante de suas determinações empíricas. Isso implica que a concepção de pessoa rawlsiana é individualista. Como o self está distante de qualquer determinação empírica, a identidade do sujeito não pode se definir a partir da comunidade em que ele está inserido. Ao aceitar a concepção de sujeito de possessão, estamos impedidos de conceber relações sociais no sentido constitutivo, ou seja, comunidades que moldam a identidade de seus membros:

Isto exclui a possibilidade de uma vida pública que, por bem ou por mal, coloca em jogo a identidade e os interesses dos seus participantes. Isto exclui a possibilidade de que propósitos e fins comuns possam inspirar um auto-entendimento mais ou menos expansivo e, então, definir a comunidade em um sentido constitutivo, uma comunidade que envolve o sujeito e não somente os objetos de suas aspirações compartilhadas. De uma forma mais geral, Rawls exclui a possibilidade do que podemos chamar de formas "intersubjetivas" ou "intrasubjetivas" 
de auto-entendimento, formas de conceber o sujeito que não partem da pressuposição de suas fronteiras. (SANDEL, 1998, p. 62)

A concepção de sujeito (e de sociedade) presente no pensamento de Rawls, segundo Sandel, exclui concepções de bem comunitárias no sentido constitutivo. Ela pressupõe uma individualidade anterior à sociedade, o que impede a constituição de uma identidade ligada à comunidade.

Ao apontar que há um "sujeito de possessão" na filosofia de Rawls, Sandel argumenta que há uma contradição conceitual no liberalismo. Uma teoria deontológica não deveria supor uma concepção de bem, mas a solução encontrada pressupõe uma concepção de pessoa que define o bem como "algo que é escolhido". Se nós aceitarmos a concepção rawlsiana de justiça como aquela que condiz com os nossos juízos ponderados, devemos implicitamente aceitar que o "sujeito de possessão" determina o modo como definimos o bem e nossa relação com a sociedade. Assim, quando Sandel aponta o contraste entre a dimensão voluntarista da ação e dimensão cognitiva, ele mostra que o liberalismo carrega consigo um modo específico de definir o bem. O contraste entre o sujeito de possessão e a comunidade em sentido "constitutivo" também aponta que o liberalismo inclui uma definição da relação entre a comunidade e os seus membros. Há uma contradição conceitual porque, apesar da intenção de separar a justiça (e o correto) de considerações relativas à boa vida, Rawls inconscientemente reestabelece uma relação entre correto e bem por via do sujeito de possessão. Para Sandel, o liberalismo pretende ser "neutro" em relação ao bem, mas não consegue.

\section{2) A avaliação}

Há duas dificuldades na avaliação da crítica de Michael Sandel, que tornam o seu diálogo com Rawls permeado por desencontros e mal entendidos. Em primeiro lugar, o livro de Sandel foi publicado num momento em que Rawls estava reorientando os objetivos de sua filosofia. As críticas podem ser avaliadas de modos distintos quando comparadas com o livro Uma teoria da justiça, por um lado, ou em relação aos textos que Rawls produziu durante as décadas de 80 e 90 , por outro. A segunda dificuldade 
é o desencontro no modo como ambos os autores definem o conceito de deontologia. Rawls não interpreta Kant do mesmo modo que Sandel, e também não define a deontologia nos mesmos termos. Por consequência, devo argumentar que, quando comparada com o livro Uma teoria da justiça, a crítica de Sandel está baseada em uma interpretação imprecisa do modo como Rawls definiu a deontologia. Quando comparadas com a "orientação" da filosofia rawlsiana durante a década de 80 , as críticas de Sandel podem ser refutadas a partir da distinção entre concepção política e as concepções abrangentes de bem. A avaliação das críticas de Sandel deve estar atenta à reorientação ocorrida na filosofia de Rawls no início da década de 80 .

Para tornar a argumentação mais clara, podemos começar com um esquema que, apesar de excluir diversas nuances conceituais, nos ajuda a definir os principais pontos do debate. Ressalto que esse esquema contém algumas simplificações que poderiam se tornar imprecisões de leitura, mas ele é válido por promover uma compreensão introdutória dos argumentos expostos a seguir. Podemos supor que uma teoria de justiça seria coerente (i.e. não há contradição conceitual) em duas situações. Cenário I: (a) a teoria pretende formular uma relação entre correto e bem, e (b) estabelece esta relação. Cenário II: (c) A teoria pretende separar correto e bem, e (d) realmente distingue os dois conceitos. Há uma contradição (cenário III) quando a teoria combina (c) e (b), ou seja, ela pretende separar os conceitos, mas estabelece uma relação. De um modo simplificado, seria possível identificar a primeira orientação de Rawls com o cenário I, ou seja, ele pretendia formular uma relação entre os conceitos, e assim o fez. A segunda orientação pode ser identificada, grosso modo, com o segundo cenário: Rawls afasta sua concepção política de justiça das concepções abrangentes de bem. A crítica de Sandel se move na contramão de Rawls porque ela supõe o cenário III, i.e., uma combinação entre (c) e (b). Comparada com a primeira orientação, a premissa (c) está equivocada: Rawls não definiu deontologia como a independência do correto em relação ao bem. Comparada com a segunda orientação, a premissa (b) é refutada, pois Rawls separa sua concepção de justiça das concepções abrangentes de bem. Em ambos os casos, Sandel erra o alvo. Este esquema, repito, não é uma representação precisa dos termos do debate, ele é apenas uma introdução aos argumentos que seguem. Uma das razões que tornam 
este esquema impreciso é a insistência de Rawls, mesmo em seus textos tardios, na afirmação de que a prioridade do correto não exclui uma relação entre correto e bem. O seu esforço, durante a segunda orientação, foi distinguir sua concepção política de justiça de concepções abrangentes de bem, o que não pró́be relação entre a justiça e algumas concepções não-abrangentes de bem (v. RAWLS, 1996, pp. 173-4,V). Voltemos à análise de texto.

No livro Uma teoria da justiça, Rawls não definiu a deontologia como a independência do correto em relação ao bem. Pelo contrário, o seu objetivo foi formular uma teoria moral que deveria estabelecer uma relação adequada entre esses dois conceitos. As concepções teleológicas, segundo Rawls, definem o bem como independente do correto, e o correto como meio para maximizar o bem. Inspirado pela ideia kantiana de autonomia, Rawls pretendeu formular uma teoria alternativa à estrutura teleológica que ele identificou nas concepções utilitaristas. Isso significava negar a independência do bem, e atribuir prioridade ao correto. Dado que Rawls identificou a independência do bem como um dos principais problemas das concepções teleológicas, a sua teoria deontológica assumiu como questão central a relação adequada entre o correto e bem. Isso significa que o projeto filosófico de Rawls durante esse período incluiu uma concepção denominada "bem como racionalidade", que deveria estar relacionada com a concepção de "justiça como equidade". A ideia rawlsiana de deontologia não pretendia excluir a formulação de uma concepção de bem, pelo contrário, ela demandava uma relação adequada entre os dois principais conceitos éticos. (v. RAWLS, pp. 24-30, \$6; REIS, pp. 38-39; FREEMAN, 2007, pp. 45-74)

$\mathrm{Na}$ terceira parte do livro Uma teoria da justiça, Rawls formulou o esboço de uma teoria do bem que poderia determinar princípios capazes de avaliar a racionalidade dos planos de vida. Assim como a teoria da justiça formula princípios para orientar o modo como a estrutura básica de uma sociedade é avaliada, a teoria do bem formula princípios para orientar o modo como as pessoas julgam os seus planos de vida e as escolhas que conduzem à realização desses planos. A concepção de "bem como racionalidade" considera como as pessoas fariam escolhas relativas aos seus planos de vida, supondo a aplicação de princípios de escolha racional e o "princípio aristotélico". A teoria do bem não afirma que 
as pessoas sempre agem racionalmente, nem que elas escolhem seus fins como algo similar ao "livre arbítrio". O bem como racionalidade apenas supõe como elas teriam feito as escolhas importantes em suas vidas, caso houvessem aplicado corretamente os princípios de escolha racional. Desse modo, Rawls formulou princípios que poderiam orientar os nossos juízos acerca do bem. Isso significa que, ao contrário da interpretação de Sandel, Rawls não identifica sua concepção de bem com as "contingências empíricas". Pelo contrário, a teoria do bem formula princípios normativos para a avaliação da boa vida. Por outro lado, a concepção de bem como racionalidade julga o valor dos planos de vida de um modo similar - mas não idêntico - à "dimensão voluntarista da ação", pois inclui uma noção de "escolha" na avaliação da boa vida. Para julgar se um plano de vida é bom ou ruim, a concepção de bem como racionalidade supõe como um indivíduo teria escolhido seu plano, caso ele houvesse aplicado corretamente os princípios de escolha racional e o princípio aristotélico. (v. RAWLS, 1999a, pp. 347-396, \$\$60-68)

Dado que projeto da teoria moral rawlsiana incluiu o desenvolvimento de uma concepção de bem, o livro Uma teoria da justiça não contém a contradição interna que Sandel acredita ter encontrado. No contexto desse livro, Rawls poderia facilmente admitir que a sua teoria moral inclui uma concepção de bem, pois uma parte importante do seu projeto consistia justamente na investigação da relação entre as duas concepções éticas. Sandel acredita ter encontrado uma contradição porque, para ele, uma teoria deontológica pretende ser independente de qualquer noção de boa vida. Ao notar que Rawls esboçou considerações acerca do bem, Sandel argumenta que há uma contradição entre, por um lado, a suposta pretensão de formular uma concepção deontológica de justiça independente do bem e, por outro, a afirmação implícita (e inconsciente) de uma concepção "voluntarista" de bem. Porém, a deontologia do livro Uma teoria da justiça visava uma relação adequada entre as concepções éticas, ou seja, uma teoria deontológica deveria formular uma concepção de bem e investigar a relação entre ela e a justiça (problema da congruência). O "sujeito de possessão" que Sandel afirma estar "implícito" na filosofia de Rawls é uma interpretação imprecisa da concepção de "bem como racionalidade", esboçada na terceira parte do livro Uma teoria da justiça. Ali, Rawls formulou conscientemente as linhas gerais de uma concepção de bem 
que faria parte de sua teoria moral deontológica. Não há, portanto, a suposta contradição conceitual que Sandel pensa ter encontrado na filosofia de Rawls desse período, pois sua teoria deontológica pretendia incluir uma concepção de bem.

Apesar de ser uma leitura imprecisa, Sandel estava correto ao afirmar que Uma teoria da justiça incluía uma concepção abrangente de bem. O objetivo de Sandel, enquanto um autor comunitarista, era defender que a justiça não deveria ser independente do bem. Seria um erro supor que Sandel advoga em favor de uma concepção "constitutiva" de bem e sociedade. Pelo contrário, ele formula as "dimensões da ação" para lançar luz sobre a noção de bem identificada no liberalismo de Rawls. Seu objetivo era criticar o conceito de deontologia e mostrar que a suposta separação entre correto e bem seria uma ilusão. Porém, Sandel estava equivocado ao supor que Rawls pretendeu formular o correto (e a justiça) independente do bem. Sua teoria original deveria incluir uma concepção de "bem como racionalidade". Ironicamente, Sandel atacou Rawls por ele ter feito aquilo que Sandel queria! Rawls incluiu uma concepção de bem em sua teoria moral e foi criticado por isso. A ironia se torna ainda maior quando se observa que, durante a década de 80 , Rawls reorientou sua filosofia na direção contrária da pretendida por Sandel e, com isso, também tornou a sua concepção liberal imune às críticas comunitaristas.

Durante a segunda fase do pensamento de Rawls, ele passou a afirmar que o fato do pluralismo impede a justificação da concepção de bem como racionalidade. Para Sandel, ao assumir a "dimensão voluntarista da ação", Rawls teria reproduzido uma concepção moderna de sujeito e, com isso, rejeitado as concepções de bem, self e comunidade do mundo antigo. Assim, Sandel sugere que a filosofia de Rawls expressa uma visão de mundo exclusivamente moderna. Rawls, por outro lado, identificou um problema diferente. Para ele, ao formular uma concepção de bem na terceira parte de Uma teoria da justiça, a sua teoria moral desconsiderou que as circunstâncias do mundo moderno incluem o fato do pluralismo. Para Rawls, a modernidade é marcada por uma grande diversidade de concepções abrangentes de bem. As pessoas seguem não apenas as concepções que Sandel define como "voluntaristas" e "constitutivas", mas também diversas outras. Durante a década de 80, Rawls passou a afirmar que, ao definir o bem de uma pessoa como "plano de vida racional 
que ela escolhe com racionalidade deliberativa" (RAWLS, 1999a, p. 372, \$65), o livro Uma teoria da justiça estava equivocado por não considerar a diversidade de concepções de bem presentes no mundo moderno. Desse modo, enquanto Sandel argumentava que Rawls formulou uma concepção excessivamente moderna de bem, o próprio Rawls passou a considerar que aquele livro não refletia adequadamente o pluralismo de concepções de bem encontradas no mundo atual, ou seja, o livro não era "moderno" o suficiente.

A resposta de Rawls foi desvincular a justiça como equidade da concepção de "bem como racionalidade" e, desse modo, "transformar a doutrina da justiça como equidade proposta em Teoria em uma concepção política" (RAWLS, 1996, p. Xli, "Introduction to the paperback edition", \3). Entre outras reformulações importantes, Rawls fez uma distinção entre "concepção de pessoa" e "natureza humana". Em Uma teoria da justiça, dado que o projeto de Rawls era formular uma teoria moral que poderia definir o correto $e$ o bem, a concepção de pessoa é identificada com a natureza humana e determina tanto a justiça quanto o bem. (v. RAWLS, 1999a, pp. 491-496, \$85; Idem, pp. 222, \$40; REIS, pp. 87-100). Sandel utiliza essa identificação para argumentar que Rawls pressupõe uma "antropologia filosófica" (sujeito de possessão) que serve como fundamento para a justiça e o bem. Assim, a concepção de natureza humana vincula a justiça liberal a uma definição da boa vida.

No artigo do construtivismo kantiano, Rawls desfez esse vínculo. A concepção de pessoa formulada ali diz respeito somente à identidade pública do cidadão. Ela está mais próxima de uma teoria da cidadania. Aquilo que Sandel identificava como uma concepção de sujeito anterior a seus fins, após esse artigo, passa a significar apenas que a identidade do cidadão não é afetada por mudanças em suas concepções de bem. Para Rawls, a liberdade significa (entre outras coisas) que um cidadão pode mudar seu plano de vida sem perder a sua cidadania ${ }^{3}$. Assim, a concepção de pessoa de Rawls não pressupõe que os seres humanos realmente possuem uma identidade anterior aos seus fins ou distinta do contexto social. Também não pressupõe que eles se veem como sujeitos de possessão. Rawls apenas diz que, no contexto público, a identidade de uma pessoa enquanto cidadã é distinta e anterior às suas concepções de bem, o que permite que ela tenha o direito de modificar suas concepções de bem sem perder o status de cidadã: 
Cidadãos, enquanto pessoas livres, têm o direito de ver as suas pessoas como independentes e não identificadas com um sistema específico de fins. Dado o poder moral de formar, revisar, e perseguir racionalmente uma concepção de bem, suas identidades públicas enquanto pessoas morais e fontes de reivindicações não são afetadas por mudanças ao longo do tempo em suas concepções de bem. (RAWLS, 1999c, p. 331)

Como a concepção de pessoa passou a definir apenas a identidade pública do cidadão, ela não determina sua identidade não-pública. O modo como um cidadão, fora do contexto público, relaciona sua identidade e seus fins não precisa tomar a forma do sujeito de possessão, nem ser avaliada segundo os princípios do "bem como racionalidade":

Os cidadãos em seus assuntos pessoais, ou dentro da vida interna de associações, podem considerar os seus fins e aspirações de forma diferente. Eles podem possuir relações e amores que eles acreditam que não poderiam se afastar; eles podem considerar impensável se ver sem algumas convicções religiosas ou filosóficas específicas. Porém, nada disso afeta a concepção de pessoa conectada com uma concepção pública de justiça e seu ideal de cooperação social. Dentro de diferentes contextos, nós podemos assumir diversos pontos de vista sobre nossa pessoa sem contradições, desde que esses pontos de vistasejam coerentes quando as circunstâncias requerem. Como sempre, nosso foco aqui é a concepção pública que está na base dos princípios de justiça social. (RAWLS, 1999c, pp. 331-2)

Ao fazer a distinção entre a identidade pública de pessoa e a não-pública, Rawls afasta sua concepção de justiça da concepção abrangente de bem como racionalidade e, portanto, desvincula sua filosofia de uma noção "voluntarista" do bem. Com essa distinção, não há mais a suposta contradição entre (c) uma concepção deontológica definida equivocadamente como independente do bem e (b) a definição do bem como "algo escolhido" pelo sujeito de possessão. Durante a primeira fase do pensamento de Rawls, (a) ele pretendeu estabelecer uma relação entre as concepções, e (b) esboçou essa relação na terceira parte do livro Uma teoria da justiça. Após a reorientação de sua filosofia, Rawls desvinculou a justiça como equidade da concepção de bem que possibilitava a interpretação de 
Sandel, ou seja, ele negou (b). Ao aceitar a concepção de justiça rawlsiana, não é mais necessário assumir uma concepção "voluntarista" do bem. $\mathrm{O}$ esforço para adaptar a justiça como equidade aos limites de uma concepção política, por oposição à concepção abrangente do livro Uma teoria da justiça, definiu uma grande parte das publicações de Rawls ao longo da década de 80 e início da década de 90. Assim, apesar de Sandel argumentar contra a separação entre correto e bem (a), a filosofia de Rawls se tornou imune às suas críticas quando se transformou no tipo de concepção liberal que Sandel pretendia combater. Com essa mudança, os pressupostos da justiça como equidade assumem apenas que um cidadão pode mudar sua concepção de bem sem perder a cidadania. A concepção política de pessoa não está mais vinculada com uma concepção abrangente do bem, e muito menos a uma identidade humana enquanto um self que escolhe os seus fins. Ela define somente as características que os cidadãos de uma democracia deveriam reconhecer nos membros de sua sociedade. Quando as críticas de Sandel são comparadas com a segunda orientação da filosofia de Rawls, o autor comunitarista aparece como alguém que confundiu o contexto público da justiça e o contexto não-público das concepções de bem. Ao distinguir os contextos, suas críticas são dissipadas. (v. FORST, 2010. pp. 15-43) ${ }^{4}$

Para Sandel, além da independência da justiça em relação ao bem, a deontologia também é definida por oposição ao consequencialismo. Em relação a este último ponto, Rawls não poderia ter sido mais claro ao afirmar que fazer essa oposição seria "loucura" (crazy) (RAWLS, 1999a, p. 26, \$6). Há uma diferença sutil, porém importantíssima, entre fundamentar princípios independentes das circunstâncias empíricas e utilizar abstrações para orientar o juízo. No primeiro caso, sugerido por Sandel, qualquer vínculo entre os princípios e a empiria prejudica a "deontologia” da concepção de justiça. Para Rawls, o contratualismo (incluindo a posição original) é um procedimento que orienta nossos juízos acerca da estrutura básica da sociedade, ao discriminar as informações relevantes para o nosso julgamento. $\mathrm{O}$ véu de ignorância indica quais informações deveriam ser "excluídas" de nossas considerações de um dado problema, enquanto os princípios de justiça atribuem pesos diversos às informações disponíveis. Dado o ordenamento lexical, informações relativas ao primeiro princípio de justiça tem prioridade em relação ao segundo. Isso significa que o 
contratualismo de Rawls pretende orientar o modo como nós, com base em nossos juízos ponderados em equilíbrio reflexivo, julgamos o ordenamento social a partir de informações empíricas. O contratualismo pretende fornecer critérios abstratos para guiar nossos juízos. Este "nós" também não é um sujeito ahistórico. Pelo contrário, ele representa os cidadãos de sociedades democráticas cujos valores são parcialmente formados pelas instituições que compõem a estrutura básica de sua sociedade. Sandel confunde o uso de ideias abstratas com uma tentativa de fundamentar princípios que negam as contingências históricas e sociais. Este distinção deve ser observada com a devida atenção porque, dado que a interpretação de Sandel é elogiosa, até mesmo um leitor simpático a Rawls poderia aceitá-la, apesar de Rawls haver negado explicitamente a oposição entre deontologia e consequencialismo. Ao aceitar a leitura de Sandel, poderíamos ser levados a assumir que a real tarefa de uma filosofia liberal (e deontológica) seria radicalizar o aspecto "apriorístico" da justiça e, desse modo, correríamos o risco de reduzi-la a formalismos vazios. Ainda pior, poderíamos ser levados a julgar políticas públicas sem considerar as suas consequências práticas 5 .

As respostas de Rawls, em O liberalismo político, parecem desconsiderar qualquer contribuição de Sandel para as correções em sua filosofia. Suas afirmações sugerem que, de seu ponto de vista, as interpretações que sustentam as críticas estavam equivocadas e a resposta deveria ser resumida a esclarecimentos contra os erros interpretativos. Este esforço pode ser observado nos momentos em que Rawls menciona a distinção entre pessoa e natureza humana (RAWLS, 1996. pp. 26-28, I, \$4.5) e na ênfase colocada sobre a relação entre correto e bem. Apesar de distinguir entre a concepção política de justiça e as concepções abrangentes de bem, Rawls insiste que mesmo uma concepção política está ligada a noções de bem. (Idem, pp. 173-4,V). Talvez essa reação possa ser explicada pelo desencontro entre as intenções de Rawls e a interpretação de Sandel. A poderosa leitura do autor comunitarista poderia levar até mesmo admiradores do pensamento rawlsiano a interpretar a tarefa do liberalismo como uma tentativa de equilibrar universalismo e contextualismo, ou como a fundamentação do correto independente do bem. Michael Sandel levanta questões importantes para a filosofia política contemporânea, e suas ideias devem fazer parte do debate atual. Porém, ao buscar uma melhor 
compreensão das questões que permeiam o liberalismo de Rawls, devemos estar atentos para o modo como ele definiu os problemas que a filosofia política deve enfrentar em nossos dias.

${ }^{1}$ A argumentação no presente artigo sustenta a si mesma. Porém, ela pode ser lida como a exploração de algumas consequências da interpretação proposta em REIS, 2012. Dado isso, irei me escusar da reprodução detalhada de argumentos desenvolvidos alhures. O presente artigo pressupõe que há uma diferença importante entre dois períodos da filosofia de Rawls: o livro Uma teoria da justiça foi orientado por objetivos diversos dos trabalhos desenvolvidos por Rawls ao longo das décadas de 80 e 90. Portanto, a reorientação na filosofia de Rawls será considerada como um pressuposto que não precisa ser justificado. Apesar disso, os principais argumentos apresentados aqui podem ser avaliados sem uma referência direta ao texto mencionado. Dado que a reorientação pode ser identificada nas Dewey Lectures (v. RAWLS, 1999c), apresentada dois anos antes da publicação do livro de Sandel, e os problemas que levaram a essa reorientação podem ser encontrados em textos publicados até sete anos antes do livro de Sandel (v. RAWLS, 1999b), seria temerário afirmar que as mudanças na filosofia de Rawls podem ser atribuídas às críticas de Sandel. Porém, a principal preocupação deste artigo não é "historiográfica", mas conceitual. O objetivo é apontar as divergências na interpretação do conceito de deontologia. Para uma análise mais detalhada do conceito rawlsiano de deontologia, (v. REIS, 2012. pp. 10-15; 28-39; 53-9; 80-88). Sobre as razões que levaram Rawls a reorientar sua filosofia. (v. idem pp. 68-73). Sobre a relação entre a justiça e as circunstâncias empíricas, (v. Idem, pp. 20-8). Sobre a segunda orientação da filosofia de Rawls, (v. Idem, pp. 103-142). Para evitar longos argumentos que, dados os atuais propósitos, seriam desnecessários, não será examinada a distinção entre teoria fraca e teoria plena do bem. Para uma análise desses conceitos (v. REIS, 2012, pp. 40-68; RAWLS, 1999a pp. 347-350, \$60; 392-396, \$68). As referências ao livro Uma teoria da justiça serão acompanhadas do número da seção (ex: "\$40" se refere à seção denominada "Kantian Interpretation of Justice as Fairness"). O livro O liberalismo político é citado com o número da "lecture" em algarismo romano, e o número das seções é acompanhado da subseção (ex: "V, \$2.1" indica a quinta "lecture", seção \$2, denominada "goodnes as rationality", e a primeira subseção que ocupa as páginas 176 e 177 da edição utilizada).

2 Sandel localiza esta concepção de natureza humana nas partes da posição original: "a solução de Rawls é restringir a descrição das partes na posição original àquelas características que todos os seres humanos possuem enquanto seres racionais livres e iguais. Grosso modo, essas características são que cada um escolhe os seus fins e avalia os bens primárioscomo instrumentais para a realização de seus fins, independente de quais sejam. É assumido que essas características são comuns a todos os seres humanos enquanto tais e, neste sentido, elas são não-contingentes” (SANDEL, 1998, p. 39). Essa interpretação está equivocada. Quando Rawls descreve sua concepção de pessoa em "Kantian Constructivism in Moral Theory" (RAWLS, 1999a), ele diz que toda a posição original é construída de forma a representar as concepções de pessoa e sociedade bem ordenada. Ele diz que as partes descrevem apenas o aspecto racional da concepção de pessoa rawlsiana. A pessoa moral também é razoável, e esta característica é

doispontos, Curitiba, São Carlos, vol. 10, n. 1, p.61-81, abril, 2013 
representada no véu de ignorância. Sandel está equivocado, portanto, ao dizer que somente as partes representam as características da pessoa moral de Rawls.

3 “um segundo aspecto da liberdade [...] é que, enquanto pessoas livres, os cidadãos reconhecem uns aos outros como tendo o poder moral de possuir uma concepção de bem. Isto significa que eles não se veem como inevitavelmente ligados à persecuçãode uma concepção específica de bem e seus fins tal como eles seguem em um determinado momento. Ao contrário, enquanto cidadãos, eles se reconhecem como, em geral, capazes de revisar suas concepções em bases racionais e razoáveis. É considerado permissível aos cidadãos se distanciar de suas concepções de bem para investigar e avaliar outros fins.” (RAWLS, 1999, p. 331).

${ }^{4}$ Para argumentar que Rawls supõe uma concepção de "sujeito de possessão", Sandel citou a primeira passagem reproduzida acima. A segunda parte do texto, que faz a distinção entre identidade pública e não-pública e é descrita por Sandel como uma "resposta deológica com uma concessão e uma distinção”, aparece apenas na penúltima página da conclusão do seu livro (v. SANDEL, p. 62, p. 182).

${ }^{5}$ Para uma análise mais detalhada sobre o uso de abstrações no pensamento de Rawls, ver REIS, 2012, pp. 20-38, 107-118; 123-143.

\section{Referências bibliográficas}

FORST, R. 2010. Contextos da Justiça. Tradução de Denílson Luís Werle. São Paulo: Boitempo.

FREEMAN, S. 2007. Justice and the Social Contract. Essays on Rawlsian Political Philosophy. New York: Oxford University Press.

SANDEL, M. 1998. Liberalism and the Limits of Justice. Second Edition. New York, Cambridge: University Press.

RAWLS, J. 1996. Political Liberalism. New York: Columbia University Press.

RAWLS, J. 1999a. A Theory of Justice. Revised Edition. Cambridge: Harvard University Press.

RAWLS, J. 1999b. Fairness to Goodness. In: FREEMAN, S. John Rawls. Collected Papers. Cambridge: Harvard University Press.

RAWLS, J. 1999c. Kantian Constructivism in Moral Theory. In: FREEMAN, S. John Rawls. Collected Papers. Cambridge: Harvard University Press. 
REIS, F. A. 2012. Da teoria moral à filosofia política: uma investigação do pensamento de John Rawls. 152 f. Dissertação (Mestrado). Faculdade de Filosofia, Letras e Ciências Humanas. Departamento de Filosofia, Universidade de São Paulo, São Paulo. 